\title{
Assessment of Asthma Control and Severity among Children According to Global Initiative for Asthma Guidelines in Sulaimani City-Iraq
}

\author{
Adnan M. H. Hamawandi \\ Department of Pediatrics, School of Medicine, University of Sulaimani./Iraq \\ Kosar M Ali \\ Department of Medicine, School of Medicine,University of Sulaimani./Iraq \\ Ali Z. Naji \\ Sulaimani Pediatric Teaching Hospital/ Iraq
}

doi: 10.19044/esj.2016.v12n3p160 URL:http://dx.doi.org/10.19044/esj.2016.v12n3p160

\begin{abstract}
Background: Asthma is a common and potentially serious chronic disease that imposes a substantial burden on patients, their families and the community.
\end{abstract}

Objective: Assessment of the level of asthma control and severity in asthmatic children in Sulaimani city according to the global initiative for asthma (GINA) guidelines.

Methods: A cross-sectional study of 82 patients who are known cases of asthma, aged 5 - 15 years , from 1st of March 2014 to 1st of August 2014.

Results: Out of 82 patients in our study, 20.8\%were classified as having intermittent asthma all of them have well controlled asthma, $42.7 \%$ of those classified as having mild persistent asthma $65.7 \%$ of them have well controlled asthma, $26.8 \%$ of those classified as having moderate persistent asthma $54.5 \%$ of them have partly controlled asthma, and 9.8\%of those classified as having severe persistent asthma the majority of them $87.5 \%$ have uncontrolled asthma and none of them reached to the controlled asthma level according to GINA guidelines. Regarding the peak expiratory flow (PFT) we notice that $58.8 \%$ of asthmatic children who were classified as having intermittent severity, their PEF measurements ranged between 160$250 \mathrm{l} / \mathrm{min}$ while those with severe persistent asthma $75 \%$ of them have readings between $50-150 \mathrm{l} / \mathrm{min}$.

Conclusion: Current levels of asthma control in the Sulaimani city fall far short of the goals specified in the GINA guidelines for asthma management. Also there is a strong correlation between PEF measurements and the level of asthma severity, 
Keyword: Asthma control; Asthma severity; GINA guidelines; Children

\section{Introduction}

Asthma is a global health problem that affects around 300 million individuals of all ages, ethnic groups, and countries (Bousquet et al., 2010). It is estimated that 250,000 people die prematurely each year as a result of asthma. Proper care of patients with asthma involves the triad of systematic chronic care plans, self-management support, and appropriate medical therapy (Bousquet et al., 2007).

The main physiological feature of asthma is episodic airway obstruction characterized by expiratory airflow limitation. The dominant pathological feature is airway inflammation, sometimes associated with airway structural (GINA 2012).

In 1993, the Global Initiative for Asthma (GINA) was formed. Its goals and objectives were described in a 1995 NHLBI/WHO Workshop Report, Global Strategy for Asthma Management and Prevention. This Report (revised in 2002 and 2006), and its companion documents, have been widely distributed and translated into many languages. A network of individuals and organizations interested in asthma care has been created and several country-specific asthma management programs have been initiated. Yet much work is still required to reduce morbidity and mortality from this chronic. The 2006 update to the Global Initiative for Asthma (GINA) guideline emphasizes the importance of evaluating asthma control, rather than asthma severity, in order to guide asthma management decisions. Classification of disease severity is a static measure that, whilst useful in initiating treatment, is less helpful in guiding subsequent treatment (GINA, 2006; Humbert, Holgate, Boulet, \& Bousquet, 2007).

Asthma control may be defined in a variety of ways. In lay terms, control may indicate disease prevention, or even cure. However, in asthma, where neither of these are realistic options at present, it refers to control of the manifestations of disease. The aim of treatment should be to achieve and maintain control for prolonged periods (Bateman et al., 2004). Therefore, the assessment of asthma control should include not only control of the clinical manifestations, but also control of the expected future risk to the patient such as exacerbations, accelerated decline in lung function, and side effects of treatment. In general, the achievement of good clinical control of asthma leads to reduce risk of exacerbations (Bateman et al., 2007). 
Table 1: levels of asthma (GINA 2012)

\begin{tabular}{|c|c|c|c|}
\hline \multicolumn{4}{|c|}{ A. Assessment of current clinical control (preferably over 4 weeks) } \\
\hline Characteristic & $\begin{array}{c}\text { Controlled (All of the } \\
\text { following) }\end{array}$ & $\begin{array}{c}\text { Partly Controlled (Any } \\
\text { measure present) }\end{array}$ & Uncontrolled \\
\hline Daytime symptoms & $\begin{array}{c}\text { None (twice or } \\
\text { less/week) }\end{array}$ & More than twice/week & \multirow{5}{*}{$\begin{array}{c}\text { Three or more } \\
\text { features of partly } \\
\text { controlled } \\
\text { asthma*† }\end{array}$} \\
\hline Limitation of activities & None & Any & \\
\hline $\begin{array}{c}\text { Nocturnal } \\
\text { symptoms/awakening }\end{array}$ & None & Any & \\
\hline $\begin{array}{c}\text { Need for reliever/ rescue } \\
\text { treatment }\end{array}$ & $\begin{array}{c}\text { None (twice or } \\
\text { less/week) }\end{array}$ & More than twice/week & \\
\hline $\begin{array}{l}\text { Lung function (PEF or } \\
\left.\qquad \mathrm{FEV}_{1}\right) \ddagger\end{array}$ & Normal & $\begin{array}{c}<80 \% \text { predicted or } \\
\text { personal best (if known) }\end{array}$ & \\
\hline
\end{tabular}

B. Assessment of Future Risk (risk of exacerbations, instability, rapid decline in lung function, sideeffects)

Features that are associated with increased risk of adverse events in the future include: Poor clinical control, frequent exacerbations in past year*, ever admission to critical care for asthma, low FEV1, exposure to cigarette smoke, high dose medications

* Any exacerbation should prompt review of maintenance treatment to ensure that it is adequate $\uparrow$ By definition, an exacerbation in any week makes that an uncontrolled asthma week $\ddagger$ Without administration of bronchodilator.

Lung function is not a reliable test for children 5 years and younger

Figure 1, describes the clinical characteristics of Controlled, Partly Controlled and Uncontrolled asthma. In clinical practice, this classification should be used in conjunction with an assessment of the patient's clinical condition and the potential risks and benefits of changing treatment.

The previous GINA documents subdivided asthma by severity based on the level of symptoms, airflow limitation, and lung function variability into four categories (fig. 2): Intermittent, Mild Persistent, Moderate Persistent, or Severe Persistent, although this classification was often erroneously applied to patients already on treatment (Taylor et al., 2008). It is important to recognize, however, that asthma severity involves both the severity of the underlying disease and its responsiveness to treatment (Cockcroft \& Swystun, 1996). Thus, asthma could present with severe symptoms and airflow obstruction, but become completely controlled with low-dose treatment. The main limitation of this previous method of classification of asthma severity was its poor value in predicting what treatment would be required and what a patient's response to that treatment might be. For this reason, an assessment of asthma control at initial presentation and periodically during treatment is more relevant and useful (Chen et al., 2007). In view of these limitations, asthma severity is now by consensus classified on the basis of the intensity of treatment required to 
achieve good asthma control (Cockcroft \& Swystun, 1996; Taylor et al., 2008). Mild asthma is asthma that can be well-controlled with low intensity treatment such as low-dose inhaled glucocorticosteroids, leukotriene modifiers or cromones. Severe asthma is asthma that requires high intensity treatment, e.g. GINA Step 4, to maintain good control, or where good control is not achieved despite high intensity treatment ("Proceedings of the ATS Workshop on Refractory Asthma," 2000).

Table 2: Classification of Asthma Severity (Khadadah et al., 2009)

\begin{tabular}{|c|c|c|c|}
\hline Classification & Symptoms/Day & Symptoms/Night & $\begin{array}{c}\text { PEF or FEV } 1 \\
\text { PEF variability }\end{array}$ \\
\hline $\begin{array}{c}\text { STEP 1 } \\
\text { Intermittent }\end{array}$ & $\begin{array}{c}<1 \text { time a week } \\
\text { Asymptomatic and } \\
\text { normal PEF between } \\
\text { attacks }\end{array}$ & $\leq 2$ times a month & $\begin{array}{l}>80 \% \\
<20 \%\end{array}$ \\
\hline $\begin{array}{c}\text { STEP } 2 \\
\text { Mild Persistent }\end{array}$ & $\begin{array}{c}>1 \text { time a week but }< \\
1 \text { time a day } \\
\text { Attacks may affect } \\
\text { activity }\end{array}$ & $>2$ times a month & $\begin{array}{c}>80 \% \\
20-30 \%\end{array}$ \\
\hline $\begin{array}{c}\text { STEP 3 } \\
\text { Moderate } \\
\text { Persistent }\end{array}$ & $\begin{array}{c}\text { Daily } \\
\text { Attacks affect activity }\end{array}$ & $>1$ time a week & $\begin{array}{c}60 \%-80 \% \\
>30 \%\end{array}$ \\
\hline $\begin{array}{c}\text { STEP } 4 \\
\text { Severe Persistent }\end{array}$ & $\begin{array}{c}\text { Continuous } \\
\text { Limited physical } \\
\text { activity }\end{array}$ & Frequent & $\begin{array}{l}<60 \% \\
>30 \%\end{array}$ \\
\hline
\end{tabular}

\section{Aim of the study}

The aim of this study is to assess the level of asthma severity among patients on treatment in Sulaimani city and their level of control according to (GINA) guidelines of asthma management and prevention, and establishment of new recommendations in asthma management in Sulaimani city.

\section{Patients and methods}

This is a cross-sectional study conducted on (82) patients who are a known cases of asthma already on treatment, aged (5 - 15) years, visiting Sulaimani Pediatric teaching hospital and the allergy and asthma center in Sulaimani city from 1st of March 2014 to $1^{\text {st }}$ of August 2014.

Data regarding personal details, asthma symptoms and using of rescue medications information were collected from each patient, in addition the peak expiratory flow (PEF) measurements was done for each patient by peak flow meter.

The age groups of participants were divided into two group; $1^{\text {st }}$ (5 10) years and $2^{\text {nd }}(11-15)$ years. Patients younger than 5 years old were 
excluded from this study because they have difficulty in using peak flow meter. Care was taken not to double list any patient with frequent visits.

Global Initiative of Asthma (GINA) Guidelines were used to assess the level of asthma control as well as the severity of the disease.

The data collected were analyzed by SPSS software version 19 using statistical test (Chi- square test) and a $\mathrm{P}$ values $<0.05$ were considered statistically significant.

\section{Results}

Out of 82 asthmatic patients in the study, 47 cases (57.4\%) were of the first age group (5 - 10 year old) , 11 (13.4\%) of them have intermittent asthma, 19 (23.1\%) of cases have mild asthma, another 14 (17.2\%) of cases have moderate asthma and only 3 (3.7\%) of cases have severe asthma. While the second group (11-15 year old) consists of 35 cases (42.6\%), 6 (7.3\%) of them have intermittent asthma, 16 (19.5\%) of cases have mild asthma, another $8(9.7 \%)$ of cases have moderate asthma and 5 (6.1\%) of cases have severe asthma, $(\mathrm{P}$ value $=0.5)$ so there is no statistically significant relationship between asthma severity class and the age of patients. This is demonstrated in table 1.

Forty eight cases (58.5\%) were males, 8 (9.8\%) of them have intermittent asthma, 21 (25.6\%) of cases have mild asthma,13 (15.9\%) of cases have moderate asthma and 6 (7.3\%) of cases have severe asthma. While 34 cases (41.5\%) were females, 9 (11\%) of them have intermittent asthma, $14(17.1 \%)$ of cases have mild asthma, 9 (11\%) of cases have moderate asthma and $2(2.4 \%)$ of cases have severe asthma, $(\mathrm{P}$ value $=0.9$ ) so there is no statistically significant relationship between asthma severity class and the sex of patients. This is demonstrated in table 1.

Table 1 also demonstrates the distribution of Asthma severity class in relation to family history of Asthma, in which 46 (56.1\%) of cases have no family histories of asthma, 10 (12.2\%) of them have intermittent asthma, 21 (25.6\%) of cases have mild asthma, another 10 (12.2\%) of cases have moderate asthma and 5 (6.1\%) of cases have severe asthma. While 36 (43.9\%) of cases were have positive family history of asthma, 7 (8.5\%) of cases have intermittent asthma, 14 (17.1\%) of cases have mild asthma, another 12 (14.6\%) of cases have moderate asthma and only 3 (3.7\%) of cases have severe asthma, $(\mathrm{P}$ value $=0.8)$ so there is no statistically significant relationship between asthma severity class and the family history of asthma in the patients.

Table 2 demonstrates the distribution of Asthma severity class in relation to Peak Expiratory Flow (PEF), we find that 6 (35.2\%) of the intermittent class cases have a PEF readings between (160-200 l/min), in the mild persistent class 14 (40\%) of them have PEF readings between (210-250 
$\mathrm{l} / \mathrm{min}$ ), in the moderate persistent class 9 (40.9\%) of them have PEF readings between (110-150 l/min), while in the severe persistent class $4(50 \%)$ of them have PEF readings between $(50-100 \mathrm{l} / \mathrm{min})$, $(\mathrm{P}$ value $=0.000)$ so there is a statistically significant relationship between asthma severity class and the PEF measurements of the patients.

Regarding the relationship between the patients GINA severity class and their level of control we find that all patients with intermittent asthma (20.8\% of our sample) have well-controlled disease. In patients with mild persistent asthma (42.7\% of our sample) we find that $23(65.7 \%)$ of them have well controlled disease, while in patients with moderate persistent (26.8\% of the sample), 12 (54.5\%) of them have partly controlled asthma, on the other hand in the severe persistent group ( $9.8 \%$ of the sample), we find that the majority 7 (87.5\%) of theme have uncontrolled asthma and no one of them had reached to the controlled asthma level according to the GINA guidelines, $(\mathrm{P}$ value $=0.000)$ so there is a statistically significant relationship between asthma severity class and the level of asthma control of the patients. This is demonstrated in table 3.

Table 3. Distribution of Asthma severity according to age, sex and family history

Variable

Intermittent

$\begin{array}{lcc}\text { Age in Years } & & \\ 5-10 & 11(13.4) & 19(23.1) \\ 11-15 & 6(7.3) & 16(19.5) \\ \text { Sex } & & \\ \quad \text { Male } & 8(9.8) & 21(25.6) \\ \quad \text { Female } & 9(11) & 14(17.1) \\ \text { Family history of Asthma } & & \\ \quad \text { Positive } & 7(8.5) & 14(17.1) \\ \quad \text { Negative } & 10(12.2) & 21(25.6)\end{array}$

GINA severity class

Persistent Moderate

$14(17.2)$

$8(9.7)$

$13(15.9)$

$9(11)$

12 (14.6)

$10(12.2)$
Total

Severe

$3(3.7) \quad 47(57.4)$

$5(6.1) \quad 35(42.6)$

6 (7.3) $\quad 48(58.5)$

$2(2.4) \quad 34(41.5)$

$3(3.7) \quad 36(43.9)$

$5(6.1) \quad 46(56.1)$

Table 4 The distribution of Asthma severity class in relation to Peak Expiratory Flow (PEF).

\begin{tabular}{|c|c|c|c|c|c|c|}
\hline \multirow{2}{*}{$\begin{array}{c}\text { PEF } \\
(\mathrm{l} / \mathrm{min})\end{array}$} & \multicolumn{5}{|c|}{ GINA Severity Class } & \multirow{2}{*}{ Total } \\
\cline { 2 - 6 } & Intermittent & Mild & Moderate & Severe & \\
\hline $50-100$ & $1(1.2)$ & $2(2.4)$ & 0 & $4(4.8)$ & 7 & 8.5 \\
\hline $110-150$ & $2(2.4)$ & $10(12.2)$ & $9(10.9)$ & $2(2.4)$ & 23 & 28 \\
\hline $160-200$ & $6(7.3)$ & $6(7.3)$ & $6(7.3)$ & $1(1.2)$ & 19 & 23.1 \\
\hline $210-250$ & $4(4.8)$ & $14(17.1)$ & $3(3.7)$ & 0 & 21 & 25.6 \\
\hline $260-300$ & $3(3.7)$ & $3(3.7)$ & $4(4.8)$ & 0 & 10 & 12.2 \\
\hline $310-350$ & $1(1.2)$ & 0 & 0 & $1(1.2)$ & 2 & 2.4 \\
\hline Total & $17(20.8)$ & $35(42.7)$ & $22(26.8)$ & $8(9.8)$ & 82 & 100 \\
\hline
\end{tabular}

P value $=0.000$

Table 5. The distribution of Asthma severity class in relation to Asthma control level. 


\begin{tabular}{|c|c|c|c|c|c|c|}
\hline \multirow{2}{*}{$\begin{array}{c}\text { Level of } \\
\text { control }\end{array}$} & \multicolumn{4}{|c|}{ GINA Severity Class } & \multirow{2}{*}{ Total } & \multirow{2}{*}{$\%$} \\
\hline & Intermittent & Mild & Moderate & Severe & & \\
\hline Controlled & $17(20.8)$ & $23(28)$ & $4(4.8)$ & 0 & 44 & 53.7 \\
\hline $\begin{array}{c}\text { Partly } \\
\text { controlled }\end{array}$ & 0 & $12(14.6)$ & $12(14.6)$ & $1(1.2)$ & 25 & 30.5 \\
\hline Uncontrolled & 0 & 0 & $6(7.3)$ & $7(8.5)$ & 13 & 15.9 \\
\hline Total & $17(20.8)$ & 35 (42.7) & $22(26.8)$ & $8(9.8)$ & 82 & 100 \\
\hline
\end{tabular}

P-value $=0.000$

\section{Discussion}

From this study we find that (53.7\%) of asthmatic patients in our sample have a well-controlled asthma and (15.9\%) were uncontrolled, also we find that all of whom asthma severity classified as intermittent have a well-controlled asthma, those with moderate asthma (54.5\%) of them have partly controlled asthma while those with severe asthma (87.5\%) of them have uncontrolled asthma, i.e. there is statistically significant ( $\mathrm{P}$ value $<0.000$ ) decrease in the level of control as the level of asthma severity increase. So current levels of asthma control in the Sulaimani city fall far short of the goals specified in guidelines for asthma management. This result is in accordance with a study, which was done in UAE 2010 (Hassan Mahboub, Santhakumar, Soriano, \& Pawankar, 2010), a study which was done in Lebanon 2010 (Bahous \& Soriano, 2010), also a study which was done in Spain 2012 (Olaguibel et al., 2012), and many other studies worldwide (Khadadah et al., 2009; Rabe, Vermeire, Soriano, \& Maier, 2000; $\mathrm{Yu}$ et al., 2010), all showed that the Asthma control achievement is suboptimal fall far short of the goals specified in guidelines for asthma management. Although poor asthma control may be due to underlying severe disease or resistance to therapy, it is far more frequently due to poor compliance, poor inhaler technique, inadequate patient education and lung function monitoring, under prescribing or environmental factors, such as allergen exposure or smoking, and also patient denial and reduced patient expectations for quality of life. Patients may also appear to have poor clinical asthma control due to incorrect diagnosis and/or significant co morbidities.

Regarding the peak expiratory flow and it relation to asthma severity we notice that (58.8\%) of asthmatic children who were classified as having intermittent severity, their PEF measurements ranged between (160-250 $\mathrm{l} / \mathrm{min}$ ) while those with severe persistent asthma (75\%) of them have readings between (50-150 l/min), so there is statistically significant decrease in the PEF measurements ( $\mathrm{P}$ value $<0.05$ ) as the level of asthma severity increase. This relationship was also noticed by many studies (Brand et al., 
1997; Kamps, Roorda, \& Brand, 2001; Cabral, Conceicao, Saldiva, \& Martins, 2002; Bacharier et al., 2004) . PFT is a reliable test for evaluating small airway obstruction ( . Forced expiratory techniques are reliable for use in most children as young as 5-6 years of age (Zapletal \& Chalupova, 2003). $\mathrm{FEV}_{1}, \mathrm{FEV}_{1} / \mathrm{FVC}$ and MMEF all relate well to asthma severity and are considered sensitive markers to predict airway obstruction ( Fuhlbrigge et al., 2001; Bacharier et al., 2008). Dissociation of symptom reports with the degree of airflow obstruction has been noted and form part of written management plans, with pulmonary function monitoring to improve asthma control. ( Milgrom et al., 2001; Bacharier et al., 2008).

In our study, we did not observe a significant influence of age and gender on the level of asthma severity, although we observe $57.4 \%$ of our sample was aged between (5-10) years, and 58.5\% was boys and the asthma severity was more severe in boys, this findings did not reach statistical significance $(\mathrm{P}$ value $=0.5$ and 0.9 ) for the age and gender respectively. This result is in accordance with that of Zedan et al (2013) who found that asthma symptom was insignificantly related to the age and gender of asthmatic children, with that of Ungar et al (2011) who found that asthma were more predominant in boys especially those younger than 10 years old, and with that of Pradel et al ( 2001) who found that older children have less severe asthma symptom and better control than younger children, and Petsios et al (2013) who also found that asthma was more severe in boys than girls. In contrast to two other in which they found that girls have more severe asthma symptom then the boys(Van De Ven, Engels, Sawyer, Otten, \& Van Den Eijnden, 2007; Nordlund, Konradsen, Pedroletti, Kull, \& Hedlin, 2011) ).

In addition we did not observe a significant influence of the family history of asthma on the level of asthma severity in our study, this is in accordance with that of Roorda et al (1994) who found that no differences, either in symptoms or lung function were demonstrated in comparison to subjects with a negative family history and concluded that neither a positive family history, nor concurrent associated allergic diseases in the child contribute to the prognosis of asthma from childhood to young adulthood.

From this study we can conclude that, although clinical trials have demonstrated that asthmatic children may reach an optimal level of disease control, which implies minimal or absent disease impact on child life, what happens in real life remains far from ideal, with long-term management falling far short of the goals set in the GINA guidelines. This objective may be reached through a tailored treatment plan taking into account the complexity of factors that contribute to achieve and maintain this objective.

\section{References:}


Bacharier, L. B., Boner, A., Carlsen, K. H., Eigenmann, P. A., Frischer, T., Gotz, M., . . . European Pediatric Asthma, G. (2008). Diagnosis and treatment of asthma in childhood: a PRACTALL consensus report. Allergy, 63(1), 5-34. doi:10.1111/j.1398-9995.2007.01586.x

Bacharier, L. B., Strunk, R. C., Mauger, D., White, D., Lemanske, R. F., Jr., \& Sorkness, C. A. (2004). Classifying asthma severity in children: mismatch between symptoms, medication use, and lung function. Am J Respir Crit Care Med, 170(4), 426-432. doi:10.1164/rccm.200308-11780C

Bahous, J., \& Soriano, J. B. (2010). [Asthma control in Lebanon the asthma insights and reality in Lebanon]. J Med Liban, 58(4), 204-209. Retrieved from http://www.ncbi.nlm.nih.gov/pubmed/21409942

Bateman, E. D., Boushey, H. A., Bousquet, J., Busse, W. W., Clark, T. J., Pauwels, R. A., . . . Group, G. I. (2004). Can guideline-defined asthma control be achieved? The Gaining Optimal Asthma ControL study. Am J Respir Crit Care Med, 170(8), 836-844. doi:10.1164/rccm.200401-033OC

Bateman, E. D., Bousquet, J., Keech, M. L., Busse, W. W., Clark, T. J., \& Pedersen, S. E. (2007). The correlation between asthma control and health status: the GOAL study. Eur Respir J, 29(1), 56-62. doi:10.1183/09031936.00128505

Bousquet, R., Dahl, N., Khaltaev, N.(2007). Global Alliance against Chronic Respiratory Diseases. Allergy, 62, 216-223. doi:10.1111/j.13989995.2007.01307.x

Bousquet, J., Kiley, J., Bateman, E. D., Viegi, G., Cruz, A. A., Khaltaev, N., . . . Zhi, L. (2010). Prioritised research agenda for prevention and control of chronic respiratory diseases. European Respiratory Journal, 36(5), 9951001. doi:10.1183/09031936.00012610

Brand, P. L., Duiverman, E. J., Postma, D. S., Waalkens, H. J., Kerrebijn, K. F., \& van Essen-Zandvliet, E. E. (1997). Peak flow variation in childhood asthma: relationship to symptoms, atopy, airways obstruction and hyperresponsiveness. Dutch CNSLD Study Group. Eur Respir J, 10(6), 1242-1247. Retrieved from http://www.ncbi.nlm.nih.gov/pubmed/9192923

Cabral, A. L., Conceicao, G. M., Saldiva, P. H., \& Martins, M. A. (2002). Effect of asthma severity on symptom perception in childhood asthma. Braz J Med Biol Res, 35(3), 319-327. Retrieved from http://www.ncbi.nlm.nih.gov/pubmed/11887209 Chen, H., Gould, M. K., Blanc, P. D., Miller, D. P., Kamath, T. V., Lee, J. H., . . . Group, T. S. (2007). Asthma control, severity, and quality of life: quantifying the effect of uncontrolled disease. J Allergy Clin Immunol, 120(2), 396-402. doi:10.1016/j.jaci.2007.04.040

Cockcroft, D. W., \& Swystun, V. A. (1996). Asthma control versus asthma severity. J Allergy Clin Immunol, 98(6 Pt 1), 1016-1018. Retrieved from http://www.ncbi.nlm.nih.gov/pubmed/8977499 
Fuhlbrigge, A. L., Kitch, B. T., Paltiel, A. D., Kuntz, K. M., Neumann, P. J., Dockery, D. W., \& Weiss, S. T. (2001). FEV(1) is associated with risk of asthma attacks in a pediatric population. J Allergy Clin Immunol, 107(1), 6167. doi:10.1067/mai.2001.111590

Hassan Mahboub, B. H., Santhakumar, S., Soriano, J. B., \& Pawankar, R. (2010). Asthma insights and reality in the United Arab Emirates. Ann Thorac Med, 5(4), 217-221. doi:10.4103/1817-1737.69109

Humbert, M., Holgate, S., Boulet, L. P., \& Bousquet, J. (2007). Asthma control or severity: that is the question. Allergy, 62(2), 95-101. doi:10.1111/j.1398-9995.2006.01308.x

Kamps, A. W., Roorda, R. J., \& Brand, P. L. (2001). Peak flow diaries in childhood asthma are unreliable. Thorax, 56(3), 180-182. doi:10.1136/thorax.56.3.180

Khadadah, M., Mahboub, B., Al-Busaidi, N. H., Sliman, N., Soriano, J. B., \& Bahous, J. (2009). Asthma insights and reality in the Gulf and the near East. Int J Tuberc Lung Dis, 13(8), 1015-1022. Retrieved from http://www.ncbi.nlm.nih.gov/pubmed/19723383

Milgrom, H., Berger, W., Nayak, A., Gupta, N., Pollard, S., McAlary, M., . . - Rohane, P. (2001). Treatment of childhood asthma with antiimmunoglobulin E antibody (omalizumab). Pediatrics, 108(2), E36. Retrieved from http://www.ncbi.nlm.nih.gov/pubmed/11483846

Nordlund, B., Konradsen, J. R., Pedroletti, C., Kull, I., \& Hedlin, G. (2011). The clinical benefit of evaluating health-related quality-of-life in children with problematic severe asthma. Acta Paediatr, 100(11), 1454-1460. doi:10.1111/j.1651-2227.2011.02359.x

Olaguibel, J. M., Quirce, S., Julia, B., Fernandez, C., Fortuna, A. M., Molina, J., . . . Group, M. S. (2012). Measurement of asthma control according to Global Initiative for Asthma guidelines: a comparison with the Asthma Control Questionnaire. Respir Res, 13, 50. doi:10.1186/1465-992113-50

Petsios, K. T., Priftis, K. N., Hatziagorou, E., Tsanakas, J. N., Antonogeorgos, G., \& Matziou, V. N. (2013). Determinants of quality of life in children with asthma. Pediatr Pulmonol, 48(12), 1171-1180. doi:10.1002/ppul.22768

Pradel, F. G., Hartzema, A. G., \& Bush, P. J. (2001). Asthma selfmanagement: the perspective of children. Patient Educ Couns, 45(3), 199209. Retrieved from http://www.ncbi.nlm.nih.gov/pubmed/11722856

Proceedings of the ATS Workshop on Refractory Asthma. (2000). Am J Respir Crit Care Med, 162(6), 2341-2351. doi:10.1164/ajrccm.162.6.ats9-00 Rabe, K. F., Vermeire, P. A., Soriano, J. B., \& Maier, W. C. (2000). Clinical management of asthma in 1999: the Asthma Insights and Reality in Europe 
(AIRE) study. Eur Respir J, 16(5), 802-807. Retrieved from http://www.ncbi.nlm.nih.gov/pubmed/11153575

Roorda, R. J., Gerritsen, J., van Aalderen, W. M., Schouten, J. P., Veltman, J. C., Weiss, S. T., \& Knol, K. (1994). Follow-up of asthma from childhood to adulthood: influence of potential childhood risk factors on the outcome of pulmonary function and bronchial responsiveness in adulthood. $J$ Allergy Clin Immunol, 93(3), 575-584. Retrieved from http://www.ncbi.nlm.nih.gov/pubmed/8151060 Taylor, D. R., Bateman, E. D., Boulet, L. P., Boushey, H. A., Busse, W. W., Casale, T. B., . . . Reddel, H. K. (2008). A new perspective on concepts of asthma severity and control. Eur Respir J, 32(3), 545-554. doi:10.1183/09031936.00155307

Ungar, W. J., Paterson, J. M., Gomes, T., Bikangaga, P., Gold, M., To, T., \& Kozyrskyj, A. L. (2011). Relationship of asthma management, socioeconomic status, and medication insurance characteristics to exacerbation frequency in children with asthma. Ann Allergy Asthma Immunol, 106(1), 17-23. doi:10.1016/j.anai.2010.10.006

Van De Ven, M. O., Engels, R. C., Sawyer, S. M., Otten, R., \& Van Den Eijnden, R. J. (2007). The role of coping strategies in quality of life of adolescents with asthma. Qual Life Res, 16(4), 625-634. doi:10.1007/s11136-006-9146-4

Yu, H. R., Niu, C. K., Kuo, H. C., Tsui, K. Y., Wu, C. C., Ko, C. H., . . . Yang, K. D. (2010). Comparison of the Global Initiative for Asthma guideline-based Asthma Control Measure and the Childhood Asthma Control Test in evaluating asthma control in children. Pediatr Neonatol, 51(5), 273278. doi:10.1016/S1875-9572(10)60053-8

Zapletal, A., \& Chalupova, J. (2003). Forced expiratory parameters in healthy preschool children (3-6 years of age). Pediatr Pulmonol, 35(3), 200207. doi:10.1002/ppul.10265

Zedan, M., Attia, G., Zedan, M. M., Osman, A., Abo-Elkheir, N., Maysara, N., . . . Gamil, N. (2013). Clinical Asthma Phenotypes and Therapeutic Responses. ISRN Pediatrics, 2013, 7. doi:10.1155/2013/824781 